controlling terminal-component responding in a heterogeneous chained schedule maintained typical patterns of responding in the initial component when the sequence produced primary reinforcement on FR 2 (a second-order chained schedule). In addition. there were systematic changes in rate between successive components of the second-order schedule. Rate in intervals preceding stimulus presentations that terminated in primary reinforcement was higher than rate in intervals preceding stimulus presentations after which primary reinforcement was omitted.

These changes in rate were not as great as those that occurred when the schedule in the terminal component was altered. The rate in the initial component of a chained schedule depends to a large extent upon the frequency of primary reinforcement in the presence of the exteroceptive stimulus in the terminal component. But apparently a stimulus can maintain responding in the initial component of a chain under a sacond-order schedule with little change in rate between successive components of the second-order schedule.

\section{REFERENCES}

BYRD, L. D., \& MARR, M. J. Relations between patterns of responding and the presentation of stimuli under second-order schedules. Journal of the Experimental Analysis of Behavior, $1969,12,713-722$.

KELLEHER, R. T. Chaining and conditioned reinforcement. In W. K. Honig (Ed.), Operant behavior: Areas of research and application. New York: Appleton-Century-Crofts, 1966. Pp. 160-212.

STUBBS, A. Contiguity of briefly presented stimuli with food reinforcement. Journal of the Experimental Analysis of Behavior, 1969 , $12,271-278$

ZIMMERMAN, D. W. Concurrent schedules of primary and conditioned reinforcement in rats. Journal of the Experimental Analysis of Behavior, 1969, 12, 261-268.

\title{
A note on variability of infrahuman FI performance*
}

\author{
BONNIE M. CLARKE, RONALD D. PRICE, and LOUIS G. LIPPMAN \\ Western Washington State College, Bellingham, Washington 98225
}

An adventitious finding of one rat's unusually high rate of responding on FI schedules was reported. This S's idiosyncratic mediation of interreinforcement intervals indicates that an FI schedule does not invariably lead to low-rate. scalloped performance in infrahumans.

In contrast to DRL schedules of reinforcement, the FI schedule does not provide a contingency for behavior control during interreinforcement intervals.
Despite the absence of such a reinforcement contingency. FI schedules are usually associated with a "scalloped" behavior pattern in infrahuman Ss. Such a pattern of noncriterial responding indicates that experienced infrahuman $\mathrm{Ss}$ mediate initial portions of successive intervals by idiosyncratic behavior that does not incorporate, or that competes with, emission of the operant.

In contrast to widely substantiated infrahuman data, performance of humans on FI schedules may take the form of DRL or scalloping performance or of high rates of responding with topographies that are typically associated with response-based reinforcement schedules (Weiner, 1969; Lippman, Leander, \& Meyer, 1970). Human Ss apparently produce more variable response topographies on $\mathrm{FI}$ schedules than do infrahumans. In studies dealing with FI schedules of reinforcement using infrahuman $S$ s, failure of a $S$ to emit a scalloped interreinforcement response topography is often interpreted as an artifact and is discounted. Thus, one may be led to the assertion that scalloping is the necessary product of FI schedules with infrahumans.

Data of the present report were gathered to provide a baseline of FI performance for an ongoing study of reinforcement schedules. The adventitious finding of atypical performance in one $S$ indicates that a low overall rate with a scalloped interreinforcement topography is likely, but is not necessarily the behavioral consequence of an FI contingency in infrahumans. Despite the likelihood that FI performance of infrahumans is more uniform than that of humans, the present data suggest that a superstitious or noncriterial behavior pattern can incorporate emission of the operant into the S's mediation of temporal intervals. The present data also suggest that this noncriterial behavior can occur in absence of any particular previous reinforcement histories or any current reinforcement contingencies that might affect the topographies of interreinforcement responding.

\section{SUBJECTS}

The Ss were four male experimentally naive Sprague-Dawley rats (Madison, Wisconsin), which were 90 days of age at the beginning of training. The Ss were housed two to a cage throughout training. APPARATUS

Two standard Grason-Stadler rat chambers (Model 1110) were fitted into separate wooden boxes that were fully lined with acoustic tile. White noise played into each box, plus the sound of a ventilating fan, masked noise from associated Grason-Stadler programming

*Reprint requests should be sent to L.G. Lippman. Department of Psychology, Western Washington State College, Bellingham, Wash. 98225 . 


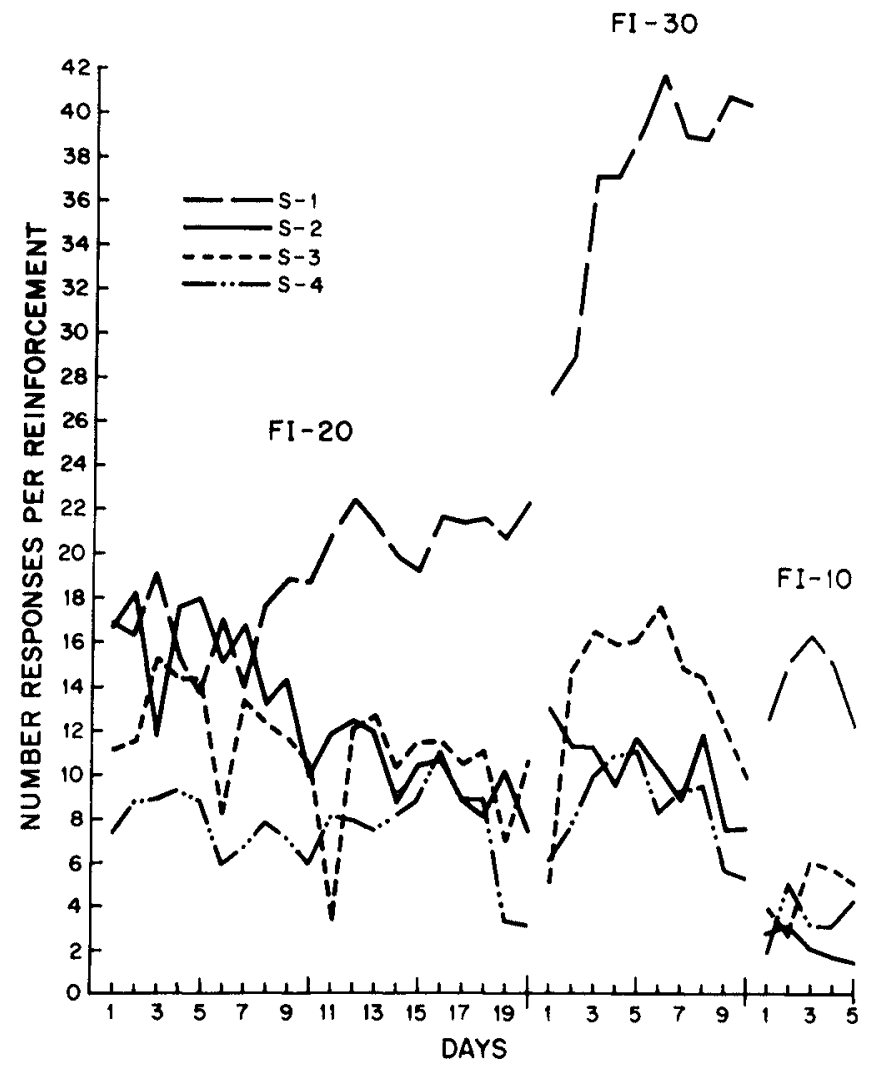

Fig. 1. Number of responses per interval for the four Ss' final 20 days of FI 20, 10 days of FI 30, and 5 days of FI 10.

equipment and Gerbrands cumulative recorders. Both the houselight and green light at the front of each box remained on throughout all sessions. Reinforcers consisted of 45-mg Noyes pellets.

PROCEDURE

Ad lib weights were recorded for 6 days Following 3 days of a $231 / 2 \cdot h$ food deprivation cycle, the four Ss were shaped to barpress until completing an entire 25-min session on CRF. All Ss were then shifted to an FI 20-sec contingency and remained on this schedule for 40 days. During shaping, CRF, and the initial 20 days of FI, the Ss were reduced in weight until reaching approximately $80 \%$ of their ad lib weights. By the end of the first 20 days of FI, the Ss were adapted to the $231 / 2-h$ deprivation cycle such that they could be maintained consistently at $80 \%$ of ad lib weight by measured postsession feedings. Following $4025-\mathrm{min}$ sessions of FI $20 \mathrm{sec}$, all Ss were shifted to FI $30 \mathrm{sec}$. Following $1025-\mathrm{min}$ sessions of FI $30 \mathrm{sec}$, all Ss were shifted to FI $10 \mathrm{sec}$ for an additional five daily sessions. Starting on the 21 st day of FI 20 , total responses and total reinforcers obtained were recorded for each daily session.

\section{RESULTS AND DISCUSSION}

Performance of the four $S s$ is presented graphically in Fig. 1 as a plot of the number of responses per reinforcement (interval) over the final 20 days of FI 20 , the 10 days of FI 30, and 5 days of FI 10. It can be extrapolated from these plots that S1 emitted an average of 1.06 responses per second during the last 10 days of FI 20, and generally maintained this response rate during FI $30 \quad(1.24$ responses/sec) and FI $10 \quad(1.43$ responses/sec). For the other three. Ss these averages ranged from 0.38 to 0.50 responses/sec in the last 10 days of FI 20 , 0.28 to 0.46 and 0.22 to 0.47 responses/sec during FI 30 and FI 10, respectively.

Inspection of cumulative records for $\mathrm{S} 1$ indicated that his postreinforcement pause rarely exceeded the time required for consummatory activity. This suggestion is in keeping with observations that were made as this $S$ 's performance began to deviate from that of the other Ss. As S 1 increased his rate over the final 10 to 12 days of FI 20, this $S$ spent progressively less time in grooming activity, exploratory behavior, periods of immobility in a corner of the chamber, or facewashing (which were observed to be the meulating behaviors performed by the other Ss that occurred most frequently in the initial portions of intervals). In contrast, S 1 adopted a posture that allowed him to look into the food magazine while still keeping his paws on the lever. This $S$ did not wait for the lever's counterweight to return the lever to its normal position, but instead, this $S$ shook the lever up and down between his forepaws. In contrast to the other Ss, and in reference to response rates, $S 1$ acquired a stable, stereotyped form of temporal mediation that happened to incorporate emission of the operant.

Despite S 1's apparent "inefficiency" in producing a disparate number of "unnecessary" responses early in successive intervals, it may be suggested that this high response rate was of some benefit. Lippman and Meyer (1967) reported that human Ss whose performance resembled scalloping or DRL response topographies tended to take longer to attain a fixed number of reinforcers than did Ss who responded continually. It may be expected that in the present instance, in which session duration was fixed, higher response rates at the termination of intervals may be associated with a larger number of reinforcers obtained in the session: The higher the response rate at the terminal portion of the interval, the sooner a reinforcer would be collected at the end of the interval and, in turn, the sooner the next interval would be initiated. Of the number of reinforcers that could be attained within a $25-\mathrm{min}$ session, S 1 obtained an average of $99.6 \%$ in the final 10 days of FI 20,99.8\% and $97.9 \%$ in FI 30 and FI 10, respectively. For the other three Ss, these percentages ranged from $92.0 \%$ to $99.6 \%$ in the last 10 days of FI $20,90.8 \%$ to $99.0 \%$ and $69.9 \%$ to $86.0 \%$ during FI 30 and FI 10, respectively. Thus, despite inefficiency in producing large numbers of responses early in intervals, the continued high response rate at the termination of intervals ensured that $S 1$ obtained nearly a maximum of the possible number of available reinforcers. This S's maximization of reinforcement is particularly evident in $\mathrm{Fl} 10$ performance, in contrast to the other three Ss whose performance consistently included an extended postreinforcement pause of at least $3.7 \mathrm{sec}$.

\section{REFERENCES}

LIPPMAN, L. G., \& MEYER, M. E. Fixed interval performance as related to instructions and to subjects' verbalizations of the contingency. Psychonomic Science. 1967, 8. 135-136.

LIPPMAN, L. G., LEANDER, J. D.. \& MEYER. M. E. Human fixed interval performance as related to response effortfulness and to initial point. Journal of General Psychology, 1970. $82,57-61$.

WEINER, $H$. Controlling human fixed-interval performance. Journal of the Experimental Analysis of Behavior, 1969. 12. 349-373. 